Diabetologia 8, 305-306 (1972)

(C) by Springer-Verlag 1972

\title{
LETTER TO THE EDITOR AND REPLY
}

Dear Sir,

The concepts presented in the paper "The effect of insulin on the incorporation of sodium $\left(1-{ }^{14} \mathrm{C}\right)$ - acetate into the lipids of the rat aorta" by R.W. Stout (Diabetologia $7,367-372,1971$ ) may be atractive to many of your readers and it is for this reason that its limitations should be made clear.

The author claims that intravenous insulin stimulates the incorporation of intravenous ${ }^{14} \mathrm{C}$-labelled acetate into rat aortic cholesterol. He does, however, offer no evidence, by further purification, that the label he finds in the position of cholesterol on thin layer chromatography is indeed cholesterol. High counting companions of cholesterol are recognized and have proven a difficulty in establishing that cholesterol synthesis takes place in the arterial wall [1]. Furthermore, in most thin layer chromatographio systems for the separation of major lipid classes, diglyceride runs together with or close to cholesterol [2]. Most workers in this field would now agree that, although cholesterol can be synthesized in the arterial wall, such synthesis does not account for more than a small part of the cholesterol which accumulates in the atherosclerotic lesion [3]. Most of the lesion cholesterol, whether free or ester, apparently comes from the blood $[4,5,6]$. On the other hand, the classic work of Zilversmit and coworkers has demonstrated that most of the phospholipid of the atherosclerotic lesion arises by local synthesis [7]. This same work describes the way in which different radioisotopically labelled precursors can be used to define the origin of an arterial lipid fraction. Dr. Stout does not apply or refer to these methods. It is not possible to draw conclusions like those of Dr. Stout without knowledge of the specific activities of the different lipid fractions of interest at least in the plasma and preferably in both plasma and arterial wall. The greater phospholipid radioactivity per unit weight of aorta with the insulin treat. ment may not represent increased incorporation of acetate into phospholipid. Insulin presumably lowered the plasma FFA concentration in the insulin treated rats and, therefore, for a given injection of ${ }^{14} \mathrm{C}$-labelled acetate, specific radioactivity of plasma FFA would be higher than in control rats. The incorporation of fatty acid into aortic phospholipids has been described $[2,3,8]$. At a higher specific radioactivity and with the same FFA uptake, such incorporation could lead to an increased radioactivity in phospholipid per unit weight of aorta.

Reports of the failure of insulin to exert an effect on lipid synthesis from acetate in the arterial wall in vitro $[9,10]$ are significant in that $\mathrm{Dr}$. Stout's findings need not be due to a direct effect of insulin on arterial wall lipid metabolism.

An alternative and as plausible explanation of Dr. Stout's data is, therefore, that with insulin treatment plasma FFA have reached a higher specific radioactivity, that these have been incorporated into diglyceride (and not cholesterol) whose aortic radioactivity has thereby increased and that either FFA and/or diglyceride (by the pathway described by Kennedy and Weiss [11]) has been incorporated (at higher specific radioactivity than in controls) into phospholipid whose radioactivity, not synthesis, has been increased. This explanation does not incriminate insulin as an "aortic wall cholesterol synthesis stimulator".

Yours faithfully,

Mark L. Wahlqvist, B. Med. Sc., M.D.

University of Uppsala

Department of Geriatrics

\section{References}

1. St. Clair, R.W., Lofland, H.B., Jr., Prichard, R.W. Clarkson, T.B.: Synthesis of squalene and sterols by isolated sogments of human and pigeon arteries. Exptl. Molec. Path. 8, 201 (1968)

2. Day, A.J., Wahlqvist, M.L. : Uptake and metabolism of ${ }^{14} \mathrm{C}$-labeled oleic acid by atherosclerotic lesions in rabbit aorta. A biochemical and radioautographic study. Circulation Research 23, 779 (1968).

3. Portman, O.W.: Arterial composition and metabolism: Fsterified fatty acids and cholesterol. Advances in lipid research 8, 41 (1970). (Edited by Paoletti, R., Kritchevsky, D., Published by Academic Press).

4. Newman, H.A.I., McCandless, E.L., Zilversmit, D. B.: The synthesis of $\mathrm{C}^{14}$-lipids in rabbit atheromatous lesions. J. biol. Chem. 236, 1264 (1961).

5. - Zilversmit, D.B.: Quantitative aspects of choles terol flux in rabbit atheromatous lesions. J. biol. Chem. 237, 2078 (1968).

6. Dayton, S.: Turnover of cholesterol in the artery walls of normal chickens. Circulation Research 7, 468 (1959).

7. Zilversmit, D.B.: The design and analysis of isotope experiments. Amer. J. Med. 29, 832 (1960).

8. Wahlqvist, M.L., Day, A.J., Tume, R.K.: Incorporation of oleic acid into lipid by foam cells in human atherosclerotic lesions. Circulation Research 24, 123 (1969).

9. - Arterial wall metabolism and atherogenesis. M.D. Thesis, University of Adelaide (1970).

10. Chattopadhyay, D.P., Martin, J.M.: Effect of insulin on the in vitro synthesis of sterol and fatty acid by aorta and liver from diabetic rats. J. Atherosclr. Res. 10, 131 (1969).

11. Kennedy, E.P., Weiss, S.B. : The function of cytidine coenzymes in the biosynthesis of phospholipids. J. biol. Chem 222, 193 (1956).

\section{Dear Sir}

The method used to study the effect of insulin on the aorta is a well-known method for testing the sensitivity of tissues to insulin in vivo [5]. It has been previously used to study liver, muscle and adipose tissue sensitivity to insulin, and was modified in my experiments only in that the aorta was the tissue studied. It must be emphasized that the sodium acetate-1. ${ }^{14} \mathrm{C}$ was injected in trace amounts, and that the insulin and isotope were administered simultaneously. Thus insulin lowered the unlabeled plasma fatty acids, newly labeled fatty acids, and labeled acetate at the same time. Because of the very rapid effect of intravenous insulin on these and other serum constituents, isolated measurements of precursor specific activity have little meaning. However, if the differences between the aortic lipids in the control and insulintreated animals were due only to changes in precursor specific activity, it would be expected that the activity in all the lipids would be increased to the same extent. In fact, the total aortic lipid radioactivity in the insulin. treated animals increased $40 \%$ while the increases in the individual lipids were: cholesterol $-19 \%$, fatty acids $4 \%$, triglyceride $-25 \%$, and phospholipid $-54 \%$.

The methods of Zilversmit et al. were designed to study, in quantitative terms, the source of atheroma cholesterol in animals with diet-induced hypercholesterolemia. The animals in my experiment were not fed 
cholesterol, and no attempt was made to assess quantitatively the importance of insulin stimulated incorporation of acetate into cholesterol in the development of arterial lesions. The relevance of experiments using diet-induced hypercholesterolemia to the common form of human atheroselerosis has recently been questioned [1].

On the thin-layer chromatography plates, the radiolabeled cholesterol appeared as a discreet band, corresponding exactly to the cholesterol standard which was run on each plate. In experiments using glucose-U-14 $\mathrm{C}$ no difference in the radioactivity of the cholesterol fraction was found in the insulin-treated animals compared with the controls [7]. If this fraction represented diglyceride, increased activity would be expected in the insulin-treated animals in keeping with the increased triglyceride radioactivity that was found. Thin-layer chromatography has been used by other workers to the study incorporation of radioactive precursors into arterial lipids [6].

Finally, the inability to demonstrate an insulin effect in vitro in no way detracts from the demonstration of an effect in vivo. In the work already quoted [5], a marked difference was found in the insulin-sensitivity of tissues studied in vivo from what had previously been found in vitro. It has been shown that arterial tissue from diabetic animals does not respond to insulin in vitro, but its metabolism is restored toward normal by prior treatment of the animals with insulin [4]. Further evidence that the artery is an insulin sensitive tissue comes from studies on an insulin sensitive lipase in arterial tissue [2], and on the enhancement by insulin of the incorporation of glucose into lipid in arterial cells grown in culture [3].
Dr. Wahlqvist's alternative explanation thus seems improbable. The weight of evidence presented by other workers as well as myself favours the conclusion that insulin can stimulate lipid synthesis in the arterial wall.

Yours sincerely,

Robert W. Stout, M.D., M.R.C.P.

\section{References}

1. Bottcher, C.J.F.: Chemical constituents of human atherosclerotic lesions. Proc. roy. Soc. Med. 64, 792795 (1971).

2. Mahler, R.: Insulin action on arterial tissue in relation to diabetes and atheroma. In "Diabetes Mellitus", ed. Duncan, L.J.P., Edinburgh University Press (1966).

3. - Parkes, A.B.: Fat synthesis in cultures of cells of arterial intima. Europ. J. Clin. Invest. 1, 137 (1970).

4. Mulcahy, P.D., Winegrad, A.I.: Effects of insulin and alloxan on glucose metabolism in rabbit aortic tissue. Amer. J. Physiol. 203, 1038-1042 (1962).

5. Rafaelson, O.J., Lauris, V., Renold, A.E.: Localized intraperitoneal action of insulin on rat diaphragm and epididymal adipose tissue in vivo. Diabetes 14, 19-26 (1965).

6. Rao, A.M., Rao, B.S.N.: Incorporation of $(1-14 \mathrm{C})$ acetate into the lipids of aortas of different species. J. Atheroscler. Res. 8, 59-67 (1968).

7. Stout, R.W.: Metabolismo lipidique dans la paroi arterielle. Journees Annuelles de Diabetologio de I'Hotel Dieu, 181-184 (1970). 